Louisiana State University

LSU Digital Commons

Faculty Publications

Department of Chemistry

8-13-2019

\title{
Coarse-Grained Models for Constant pH Simulations of Carboxylic Acids
}

Naeyma N. Islam

University of New Orleans

Arjun Sharma

University of New Orleans

Gaurav Gyawali

University of New Orleans

Revati Kumar

Louisiana State University

Steven W. Rick

University of New Orleans

Follow this and additional works at: https://digitalcommons.Isu.edu/chemistry_pubs

\section{Recommended Citation}

Islam, N., Sharma, A., Gyawali, G., Kumar, R., \& Rick, S. (2019). Coarse-Grained Models for Constant pH Simulations of Carboxylic Acids. Journal of Chemical Theory and Computation, 15 (8), 4623-4631.

https://doi.org/10.1021/acs.jctc.9b00159

This Article is brought to you for free and open access by the Department of Chemistry at LSU Digital Commons. It has been accepted for inclusion in Faculty Publications by an authorized administrator of LSU Digital Commons.

For more information, please contact ir@lsu.edu. 


\title{
Coarse-grained models for constant $\mathrm{pH}$ simulations of carboxylic acids
}

\author{
Naeyma N. Islam, ${ }^{\ddagger}$ Arjun Sharma, ${ }^{\ddagger}$ Gaurav Gyawali,,$\ddagger$ Revati Kumar, $₫$ and \\ Steven W. Rick, \\ $\ddagger$ Department of Chemistry, University of New Orleans, New Orleans, LA, 70148 \\ \Department of Chemistry, Louisiana State University, Baton Rouge, LA, 70808 \\ E-mail: srick@uno.edu
}

\begin{abstract}
A model for carboxylic acids, in both the protonated and de-protonated states, is developed in which hydrogen interaction sites are not used and all interactions are short ranged. A method for constant $\mathrm{pH}$ simulations, which exploits these features of the model, is developed. The constant $\mathrm{pH}$ method samples protonation states by making discrete Monte Carlo steps and is able to efficiently move between states in two steps. The method is applied to the polymer poly(methacrylic acid), a pH-responsive polymer that undergoes structural changes as a function of $\mathrm{pH}$. The model is able to reproduce the structural changes induced by $\mathrm{pH}$.
\end{abstract}




\section{Introduction}

The aggregation of acidic macromolecules is strongly influenced by $\mathrm{pH}$. Long chain fatty acids have a rich phase diagram? ${ }^{\text {? }}$ and liposomes containing these molecules are potential drug delivery materials. ? ? Poly-acidic pH-responsive polymers show large reversible structural changes induced by $\mathrm{pH}$ and have a wide range of applications. ? The structure of the acidic macromolecules is determined by the balance of the different interactions and how they shift as $\mathrm{pH}$ is changed. In addition to successfully reproducing these interactions, the models need to be computationally efficient for large-scale simulations of multiple macromolecules.

The coarse-grained (CG) approach based on the Stillinger-Weber (SW) potential $^{?}$ gains efficiency through an elimination of interaction sites on hydrogen atoms and a significant reduction in the range of the interactions. Despite the lack of hydrogen sites and Coulombic interactions, the SW approach has been shown to accurately model water, ? ? ? hydrophobic interactions, ? ? aqueous salt solutions, $^{\text {? }}$ and water soluble polymers. ${ }^{\text {? }}$ The model uses a combination of two- and three-body interactions to establish nearest-neighbor coordination numbers, geometries, and energy scales. The models retain a molecular representation of the system, including water, unlike models which coarse-grain on a larger scale (typically mapping three or four heavy atoms onto one interaction site), ? while having similar computational efficiencies, ${ }^{?}$ with the larger number of interaction sites (relative to other CG models) compensated for with the reduced range of the potential. The SW-based models are an appealing choice for simulating aqueous macromolecules, since they retain a molecular level description and the $\mathrm{SW}$ water model $\mathrm{mW}$ is of comparable accuracy to conventional all-atom models.

In conventional molecular dynamics simulations, bonds are not broken or made, so 
the protonation state of an acid or base remains constant. In constant-pH $(\mathrm{CpH})$ simulations, ${ }^{?}$ protonation states are allowed to change in response to $\mathrm{pH}$ and structural changes. These approaches can be grouped into types, depending on how the solvent is treated. ${ }^{?}$ The simplest, most commonly used $\mathrm{CpH}$ method uses a continuum model for water and Monte Carlo moves between different protonation states are taken.? ? This can work because the continuum solvent responds instantaneously to the protonation state change, so there is always equilibrium between solvent and solute. A second approach uses explicit solvent? ? in which the protonation state changes continuously, in equilibrium with the slow solvent response. A third hybrid approach combines simulations with explicit solvent with protonation state moves based on continuum solvent models. ? ? ' CG models have been used with both implicit solvent models ${ }^{?}$ ? and CG water models. ${ }^{?}$ A disadvantage of the explicit solvent $\mathrm{CpH}$ methods is that the use of continuous protonation states leads to significant time spent in unphysical states. ${ }^{?}$ For a polymer or collection of acidic molecules near the pKa there is a very small chance that all acidic groups will be in a physical state and so structures that correspond to completely physical states will be rare. The SW approach is then well-suited for use with $\mathrm{CpH}$ simulations, since the lack of hydrogen sites means the solvent response will be quicker since it involves translational and not orientational motion. The difference between the protonated and de-protonated states in the CG model just involves a change in the potential parameters and not a change in the number of interaction sites. In this paper, we developed a $\mathrm{CpH}$ model in which transitions between protonated and de-protonated states are made through discrete jumps, with one intermediate states. This is intermediate method between implicit solvent models, which make the jump in one step, and atomistic solvent models, which use a continuous variable to make the jump.

In this work, we have developed SW models for protonated and de-protonated 
carboxylic acids, which we apply to poly(methacrylic acid) (PMAA). In the PMAA studies, we show how the protonation states, tacticities, and counter ions influence the structure of the polymer. In $\mathrm{CpH}$ studies, we further explore the effects of local polymer structure and counter ions in the $\mathrm{pH}$ response.

\section{Methods}

Potential model. The Stillinger-Weber potential? ${ }^{\text {? }}$ uses two- and three-body potentials, as given by

$$
E=\sum_{i} \sum_{j>i} \phi_{2}\left(r_{i j}\right)+\sum_{i} \sum_{j \neq i} \sum_{k>j} \phi_{3}\left(r_{i j}, r_{i k}, \theta_{j i k}\right)
$$

where $\mathrm{r}_{i j}$ is the distance between atoms $i$ and $j$ and $\theta$ is the angle between atom $i$ and its neighbors $j$ and $k$. The two-body term has this form,

$$
\phi_{2}\left(r_{i j}\right)=A \epsilon_{i j}\left[B\left(\sigma_{i j} / r_{i j}\right)^{4}-1\right] \exp \left(\sigma_{i j} /\left(r_{i j}-a_{i j} \sigma_{i j}\right)\right)
$$

and the three-body term has this form

$\phi_{3}\left(r_{i j}, r_{i k}, \theta_{j i k}\right)=$

$$
\lambda_{i j k} \epsilon_{i j k}\left[\cos \theta_{j i k}-\cos \theta_{0}\right]^{2} \exp \left(\gamma \sigma_{i j} /\left(r_{i j}-a_{i j} \sigma_{i j}\right)\right) \exp \left(\gamma \sigma_{i k} /\left(r_{i k}-a_{i k} \sigma_{i k}\right)\right)
$$

Both terms are zero at $r_{i j}$ greater than $a_{i j} \sigma_{i j}$. The three-body term is necessary for particles with highly directional interactions, like hydrogen bonds. There are no Coulombic interactions for the model, but for atoms with formal charges (sodium ions and the oxygens on the carboxylate group) a Yukawa potential is used between 
pairs with the same charge, to treat charge repulsion. The Yukawa potential has the form?

$$
\phi_{Y}\left(r_{i j}\right)=A_{Y} e^{-\kappa r_{i j}} / r_{i j} \quad r_{i j}<r_{c}
$$

The parameters A, B, $a_{i j}, \gamma, \kappa$, and $r_{c}$ are taken from previous studies $(\mathrm{A}=7.049556277$, $\mathrm{B}=0.6022245583, a_{i j}=1.80, \gamma=1.20, \kappa=1.80 \AA^{-1}$, and $\left.r_{c}=7.0 \AA\right)$ ? ? ? ? The welldepth, $\epsilon$, and length scale, $\sigma$, parameters for $\phi_{2}$, the angle, $\theta_{0}$, and energy-scale, $\epsilon_{i j k}$ and $\lambda_{i j k}$, parameters for $\phi_{3}$, and the energy scale, $A_{Y}$, parameter for $\phi_{Y}$ are taken to be adjustable.

The bond stretch, $E=k_{b}\left(r-r_{0}\right)^{2}$, and bond angle terms, $E=k_{\theta}\left(\theta-\theta_{0}\right)^{2}$, we taken from OPLS-UA values? (Table ??). Bonded terms for oxygen atoms are taken to be independent of protonation state or bond order. In Table ??, CHn refers to all carbon atoms with two or three hydrogen atoms, CT is a quaternary carbon, $\mathrm{CO}$ is the carbon atom of the carboxyl group, and $\mathrm{O}^{*}$ is all oxygens of the carboxyl group. The torsional parameters use the Fourier form

$$
E(\theta)=V_{1}(1+\cos \phi)+V_{2}(1-\cos 2 \phi)+\frac{1}{2} V_{3}(1+\cos 3 \phi)
$$

The torsional parameters for CHn-CT-CO-O* are taken from the OPLS-AA value. ? For the CO-CT-CHn-CT and CHn-CT-CHn-CT dihedral, which would have a hydrogen atom contribution to the dihedral energy, we modified the CG terms so that the CG torsional energies matched the all-atom (AA) energies. For four atoms along a bonded sequence $\mathrm{ABCD}$, with atom $\mathrm{B}$ also bonded to two hydrogen atoms, then the condition that the $\mathrm{CG}$ and $\mathrm{AA}$ are equal is

$$
E_{C G}(\phi)=E_{A B C D}(\phi)+E_{H B C D}\left(\phi+120^{\circ}\right)+E_{H B C D}\left(\phi-120^{\circ}\right)
$$


where $E_{A B C D}(\phi)$ is the $\mathrm{AA}$ torsional energy for atoms $\mathrm{A}, \mathrm{B}, \mathrm{C}$, and $\mathrm{D}$. Using simple trigonometry identities leads to $\mathrm{V}_{1}=\mathrm{V}_{1 A}-\mathrm{V}_{1 H}, \mathrm{~V}_{2}=\mathrm{V}_{2 A}-\mathrm{V}_{2 H}$, and $\mathrm{V}_{3}=\mathrm{V}_{3 A}+2 \mathrm{~V}_{3 H}$, where $\mathrm{V}_{i A}$ is the dihedral parameter with the heavy atom $\mathrm{A}$ and $\mathrm{V}_{i H}$ is the parameter with the hydrogen atom. The torsional parameters are given in Table ??.

Parameter optimization. Parameter for water, ${ }^{?}$ the carbon atom types $\mathrm{CHn}$ and $\mathrm{CT},{ }^{?}$ and the sodium ion ${ }^{?}$ are taken from previous studies. Non-bonded parameters for $\mathrm{CT}$ were taken to be equivalent to $\mathrm{CH} 2$. Interactions between the water and the carboxylic acid atom types are optimized to reproduce the water-solute pair correlations of all-atom models, for aqueous acetate and acetic acid. These atoms types are $\mathrm{CO}, \mathrm{COA}, \mathrm{OH}, \mathrm{O}$, and $\mathrm{OA}$, where $\mathrm{OH}$ refers to the protonated oxygen, $\mathrm{O}$ to the oxygen with the double bond, $\mathrm{OA}$ to the carboxylate oxygen, $\mathrm{CO}$ to the carbon of the protonated acid and COA to the carbon atom of the de-protonated acid, as shown in Figure ??. For comparison, the TIP4P/2005? water and OPLS-AA? solute all-atom models are used. The free energy of hydration for acetic acid was also used to parameterize the model, against the experimental value. ? ${ }^{?}$ The interactions between $\mathrm{OH}-\mathrm{O}, \mathrm{OH}-\mathrm{OH}$, and $\mathrm{OH}-\mathrm{OA}$ are taken to be similar to $\mathrm{OH}-$ water interactions, but slightly stronger. Experimental ? ? and simulation ${ }^{?}$ ? studies indicate the hydrogen bonds between carboxyl groups stabilize the self-assembly of PMAA at low $\mathrm{pH}$, suggesting that they should be stronger than carboxyl-water hydrogen bonds. Interactions between $\mathrm{OA}$ atoms are taken to be purely repulsive, using the Yukawa potential. We took the full ion charge as modeled by the SW approach? ${ }^{\text {and dis- }}$ tributed it equally on the two oxygen atoms. Reducing the charge by a half, reduces $\phi_{Y}(r)$ by $1 / 4$, so we take $A_{Y}$ to be equal to the sodium or chloride $A_{Y}$ divided by four. We did not otherwise optimize this parameter. Three-body interactions were only used for interactions treating hydrogen bonds, on water or the $\mathrm{OH}$ group on the carboxylic acids. Interactions between the OA and sodium ions were chosen so that 
they reproduce the position and energy of the minimum of the potential of mean force between acetic acid and sodium.? ? ?

Constant pH simulations. For each carboxylic acid group, there are two states, a protonated state with potential energy $\mathrm{E}_{0}$, and a de-protonated state with energy $\mathrm{E}_{1}$. With the $\lambda$-dynamics method, ? ? for continuous values of $\lambda$, the potential energy function is

$$
E(\lambda)=(1-\lambda) E_{0}+\lambda E_{1}-\lambda \Delta G_{m}+\lambda k_{B} T \ln (10)\left(p H-p K a_{m}\right)
$$

where $\Delta G_{m}$ is the pre-calculated free energy difference between the protonated and de-protated states for the isolated monomer, $\mathrm{k}_{B}$ is Boltzmann's constant, and $\mathrm{pKa}_{m}$ is the experimental pKa of the isolated monomer. In the present approach, rather than let $\lambda$ be a continuous variable, we only allow it to have discrete values. The fewer intermediate states the better, since the simulation will spend less time in unphysical states, but with too few states, jumps between them can become too rare. For our application, we found that the method works with only one intermediate state. The choice of $\lambda$ for the intermediate state can be optimized to maximize the number of transitions (see below). Intermediate states are defined with interaction parameters interpolated between the protonated and de-protonated parameters,

$$
\alpha_{\lambda}=(1-\lambda) \alpha_{0}+\lambda \alpha_{1}
$$

where $\alpha$ represents a potential parameter, which includes $\epsilon, \sigma$, and the three-body 
parameters. The simulation then jumps between the states, with energies give by

$$
E= \begin{cases}E_{0} & 0 \\ E_{\lambda}-\Delta G_{\lambda}+\lambda k_{B} T \ln (10)\left(p H-p K a_{m}\right) & \lambda \\ E_{1}-\Delta G_{1}+k_{B} T \ln (10)\left(p H-p K a_{m}\right) & 1\end{cases}
$$

where $\Delta G_{\lambda}$ is the free energy of state $\lambda$ relative to state 0 and $\Delta G_{1}$ is the free energy of state 1 relative to state 0 . (In equation ??, $\mathrm{E}_{0}, \mathrm{E}_{\lambda}$, and $\mathrm{E}_{1}$ refer potential energy functions, with the different force field parameters.) The constant $\mathrm{pH}$ simulations would jump between the states using the Metropolis algorithm. The free energies, $\Delta G_{\lambda}$ and $\Delta G_{1}$, for the monomer in water are found from standard free energy calculations. These were down using free energy perturbation theory with 11 intermediate states, each simulated for $1 \mathrm{~ns}$, using the $\mathrm{CG}$ model. The values are $\Delta G_{\lambda}=-35.15$ $\mathrm{kcal} / \mathrm{mol}$ and $\Delta G_{1}=-41.95 \mathrm{kcal} / \mathrm{mol}$. The monomer is taken to be trimethylacetic acid, for the PMAA calculations, using the experimental value of 5.03 for $\mathrm{pKa}_{m}$.

Sampling over protonation states can be helped using replica exchange, in which simulations at different $\mathrm{pH}$ are done simultaneously and configurations are swapped

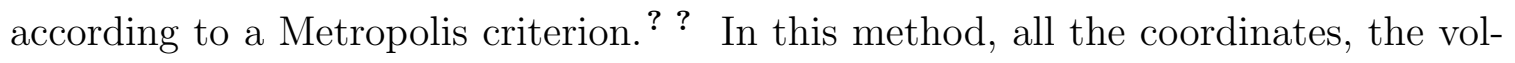
ume, and the protonation states of one simulation are swapped with another. Swaps between replicas $i$ and $j$ are accepted with a probability, $\mathrm{P}_{i j}$, based on the energy difference $\Delta \mathrm{E}_{i j}$. From Equation ??, the exchange probability is

$$
P_{i j}=\min \left[1, e^{\left(N_{i}-N_{j}\right) \ln 10\left(p H_{i}-p H_{j}\right)}\right]
$$


where $N_{i}$ is the sum over the $\mathrm{N}_{p}$ protonation states of replica $i$,

$$
N_{i}=\sum_{k=1}^{N_{p}}\left(1-n_{i, k}\right)
$$

The quantity $n_{i, k}$ gives the protonation state value (as given by the numbers $0, \lambda$, or 1) of the $k^{\text {th }}$ titratable group for replica $i$. The implementation used follows this sequence:

- For a range of pH values, run at fixed protonation states for 100 steps (0.5 ps).

- Attempt a change in protonation state, for every ionizable group, in random order. For each group, attempt to move to a neighboring state (between 0 and $\lambda$ or $\lambda$ and 1). For the middle $\lambda$ state, randomly choose to move to the 0 or 1 state. For the de-protonated state, randomly choose one of the two carboxyl oxygens to attempt to protonate. Accept or reject this protonation state move, and change the protonation state if the move is accepted, then move on the next randomly chosen group.

- After 1000 cycles of constant pH simulations (0.5 ns total), attempt a replica exchange swap between replicas at adjacent $\mathrm{pH}$ values. We alternate between a swap step involving the first and second, third and forth, and so on, and the second and third, forth and fifth, and so on.

- The constant $\mathrm{pH}$ replica exchange cycle was repeated 50 times, so that each $\mathrm{pH}$ value was simulated for a total of $25 \mathrm{~ns}$.

It was important to use a different random number seed to assign velocities at the beginning of each simulation. Otherwise the constant $\mathrm{pH}$ simulations, resulting from a 
number (40 times 1000) of short simulations, will not reproduce the results of a single long simulation for the highest and lowest $\mathrm{pH}$. At these $\mathrm{pH}$ values, the protonation states are essentially constant and the constant $\mathrm{pH}$ results should be the same as conventional simulations.

Simulation details. The CG simulations used LAMMPS, ? with a 5 fs time step in the isothermal-isobaric (TPN) ensemble, with temperature and pressure controlled using a Nosé-Hoover thermostat, with a 100 fs damping constant, and a barostat, with a damping parameter of $1000 \mathrm{fs}$, at a temperature of $300 \mathrm{~K}$ and a pressure of 1 bar,respectively. The all-atom simulations used the Gromacs simulation package? using TIP4P $/ 2005^{?}$ water and OPLS-AA ${ }^{?}$ solute models. The free energy calculations for the hydration free energy of acetic acid were done using finite difference thermodynamic integration (FDTI), ${ }^{?}$ using a soft core potential to avoid singulari-

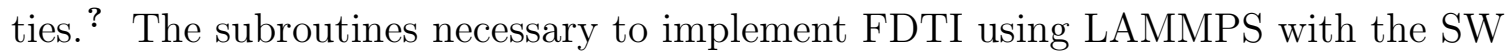
potentials are available on github. ${ }^{?}$ The constant $\mathrm{pH}$ simulations were carried out using bash shell scripts, which calls LAMMPS with the appropriate input files for the specific protonation state, and accepts or rejects protonation state changes and replica swaps as described above. The sodium-acetate potential of mean force calculations were run for 2.5 microseconds. The constant $\mathrm{pH}$ simulations used a number of sodium ions equal to the number of acidic groups, at a concentration of $0.25 \mathrm{M}$. Simulations for the de-protonated 20mer were ran at a number of sodium ion concentrations, by varying the number of water molecules.

\section{Results}

The potential parameters are given in Tables ??, ?? and ??. Two-body parameters not given are obtained from the Lorentz-Berthelot combining rules: $\epsilon_{A B}=$ 
$\left(\epsilon_{A A} \epsilon_{B B}\right)^{1 / 2}$ and $\sigma_{A B}=\left(\sigma_{A A}+\sigma_{B B}\right) / 2$. Three-body parameters not given are zero. The coarse-grained models were parameterized to reproduce the pair correlations of all-atom models, for aqueous acetate and acetic acid (Figure ??). The CG model does fairly well at reproducing the water structure near the three different oxygen types, in terms of the positions of the first solvation shell and the peak heights. There is not a large peak around the acetic acid oxygen atoms, particularly for the carbonyl oxygen. The pair correlation function between the methyl carbon on (protonated) trimethylacetic acid and water can be used to check how the model captures the hydrophobic interaction (Figure ?? (D)). For these interactions, we used previously published values, optimized for alkanes. ${ }^{\text {? }}$ The CG and AA models show similar small peaks in about the same positions, giving us some confidence that the CG potential will model the hydrophobic part of PMAA with sufficient accuracy. The free energy of hydration for acetic acid was also used for parameterization. The model gives a value of $-6.6 \pm 0.1 \mathrm{kcal} / \mathrm{mol}$. The experimental value is $-6.69 \mathrm{kcal} / \mathrm{mol}$. ? ?

The potential of mean force (PMF) between the central carbon of the acetate ion and the sodium ion (Figure ??) shows both a bidentate minimum at $2.7 \AA$ and a slightly deeper monodentate minimum at $3.3 \AA$, as well as a shallow solventseparated minimum around $5 \AA$. The PMF from ab initio molecular dynamics for the acetate-sodium PMF finds that the contact pair is stable by $1 \mathrm{kcal} / \mathrm{mol}$ over

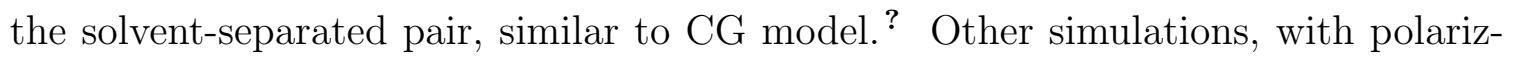
able potentials ${ }^{?}$ and non-polarizable force fields optimized to reproduce the osmotic pressure, ${ }^{?}$ find a similarly shallow contact pair minimum. The free energy difference between the mono- and bidentate states is small and depends on the force field or $a b$ initio method.

Structural changes are examined both on the length scale of the entire polymer through the radius of gyration and at local, nearest-neighbor scale, through the 
fraction of proximal neighbors. ${ }^{\text {? }}$ The distance between neighboring carboxylic acid groups fall into two groups, depending on the backbone conformation. The carbonyls can be on the same side, in a conformation termed proximal, or on opposite sides (at a dihedral angle equal to 120 degrees), termed distal. For the syndiotactic polymer, if all backbone dihedral angles are equal to 180 degrees, then the carboxyl groups are distal and for the isotactic polymer, this extended backbone conformation puts the carboxyl groups as proximal. The local structure can be described by the fraction of neighboring groups that are proximal, $\mathrm{f}_{\text {proximal }}$. This fraction was found using the distance between the carbonyl carbon atoms. If that distance is less than $3.7 \AA$, then the conformation is proximal, otherwise it is distal.

The properties of PMAA with 20 repeat units show that the model undergoes a structural transition induced by the change in the protonation states (Table ??). The radius of gyration, $\mathrm{R}_{G}$, changes from about $6 \AA$ for the protonated state to 10 $\AA$ for the de-protonated state. Similar changes have been reported using all-atom simulations. ? ? Table ?? compares our results with simulations of PMAA of the same length, but different force fields, tacticities and counter-ion concentrations. ? ? Sulatha and Natarajan? give values for two different force fields. The $\mathrm{R}_{G}$ for the de-protonated form shows a small dependence on sodium concentration, decreasing as the sodium concentration increases. The local structure changes from mostly proximal for the isotactic form and mostly distal for the syndiotactic form to about mostly distal for both tacticities. The fraction of proximal values for both protonation states and tacticities are similar to all-atom studies.

Sodium ions are taken to be associated with the polymer if they are less than 4.0 $\AA$ from a carboxylate carbon. The amount of sodium ion in contact with the polymer increases from about 3 at $0.25 \mathrm{M}$ to about 5 at $0.5 \mathrm{M}$.

Constant pH simulations. Using one intermediate state, as defined by Eq. ??, 
the method can jump between protonation states (Fig. ??). Using trimethylacetic acid as a test case, we found that value of $\lambda$ equal to 0.70 gives even transitions between the two states. A larger $\lambda$ value results in more transitions between the intermediate and the final state, but fewer transitions between the intermediate and the initial state. A smaller $\lambda$ value does just the opposite, with more transitions between the initial and intermediate state. This is the value used for subsequent constant $\mathrm{pH}$ simulations, for which we found that $\lambda$ samples between protonation states effectively. Calculations were run for chain lengths, ranging from 1 to 20. For the 20mer, we simulated both the syndiotactic and isotactic form. The simulations used a number of sodium counter ions equal to the length of the chain, at a concentration of $0.25 \mathrm{M}$. The titration curves are shown in Figure ??. The results are fit to the Hill equation

$$
\text { fraction de }- \text { protonated }=1 /\left(10^{n(p K a-p H)}+1\right)
$$

where $\mathrm{pKa}$ is minus the log of the acid dissociation constant and $\mathrm{n}$ gives the degree of cooperativity. Those values are given in Table ??. The pKa of the monomer, trimethylacetic acid, is, by construction, close to the experimental value of 5.03. The pKa of the dimer increases by about $0.8 \mathrm{pH}$ units and $\mathrm{n}$ is near one. The 20 mer has a pKa, for both tacticities, around 8.4 and a cooperativity near 0.6. For comparison, the experimental value for PMAA has been reported to be $5.5,{ }^{?} 6.25^{?}$ and $7.3 .^{?} \mathrm{~A}$ large conformation change of PMAA has been observed over the $\mathrm{pH}$ range from 5 to 6, suggesting the pKa is about 5.5. ? Quantum calculations give a pKa of 5.22 for the dimer and 6.06 for the tetramer. ${ }^{?}$ All-atom constant $\mathrm{pH}$ simulations give a $\mathrm{pKa}$ for the 20 mer close to $5 .^{?}$

As the simulation jumps between protonation states, intermediate states are visited, so some of the structures generated do not correspond to physical, real states. 
The fraction of states that correspond to completely physical states (that is, those with no intermediate states on any acidic groups) is shown in Figure ??. In all cases, this fraction is above about 0.45 . As might be expected, there are the most un-physical states near the pKa, when transitions between states are frequent. The number of unphysical configurations does not increase as the number of groups increase; we get no more unphysical states for the 20mer than for the monomer. For a monomer, transitions between states are governed only by solvent fluctuations. For the longer chains, transitions are also induced by polymer motion, which are slower. This decreases the frequency of transitions, leading to fewer intermediate states. In the data presented below, we only use the physical states in generating averages, even though the averages generated with all the configurations and those just with the physical configurations are very similar.

To further characterize the $\mathrm{pH}$ response, each carboxylic acid group can be grouped according to its local structure. If a carboxyl group has all neighbors in a distal geometry then the pKa is less than if it has at least one proximal neighbor (Table ??). For the dimer, the difference in the distal and proximal pKa is about 1 and for the $20 \mathrm{mer}$, the difference is 0.5 for the isotactic and 0.7 for the syndiotactic. This shift is about the same as the all-atom constant $\mathrm{pH}$ results. ${ }^{\text {? }}$ In the distal geometry $\mathrm{n}$ is about 1 , indicating no cooperativity, and changes to about 0.5 in proximal geometries, as repulsions between adjacent groups lead to negative cooperativity. When the groups are close, the loss of a proton, creating the negatively charged carboxylate, makes it more difficult for a neighboring group to lose a proton. Sodium ions also affect the pKa. By comparing structures which had a sodium ion near a carboxylate carbon with those that do not, the pKa shows a large decrease when a sodium ion is near. For the 20mers, this is over $2.5 \mathrm{pH}$ units.

Structural changes for the 20mer as a function of $\mathrm{pH}$ are shown in Figure ??. The 
radius of gyration shows an abrupt change near the pKa. The fraction of proximal neighbors show a more gradual change. The local change, as given the fraction proximal, begins at a lower $\mathrm{pH}$ than the global change, as given by the radius of gyration.

\section{Conclusion}

The CG model is able to reproduce properties of both the protonated and deprotonated states. For PMAA, the models capture the $\mathrm{pH}$ response on both the local level, with a change in the number of fractional neighbors, as well as the larger scale change as given by the radius of gyration (Table ?? and Figure ??). Neighboring carboxylate groups get further from each other and the entire polymer expands due to repulsive interactions. For all-atoms models, the expansion is induced by Coulombic repulsions between the charged groups and a strong attraction to the solvent, which can draw the groups away from each other and into solution. For the CG model, the repulsions are due to the Yukawa potential and the three body terms involving the carboxylate oxygens and water molecules. These interactions are short-ranged, by design. In order to make repulsive interactions to cause the structural change, they need to be sufficiently strong over their short range. The model overestimates the pKa of the polymers, and the structural $\mathrm{pH}$ response occurs at a larger $\mathrm{pH}$, possibly because it overestimates the strength of the short-ranged interactions in order to compensate for the lack of long-ranged interactions.

The constant $\mathrm{pH}$ method is able to use the lack of hydrogen interaction sites to result in an efficient method for sampling over protonation states. The method enable Monte Carlo moves between the protonated and de-protonated state using one state in between (Figure ??). The method is intermediate between the methods which use 
continuum solvent methods, and can switch directly between the two states, ${ }^{?}$ and those that use explicit solvent, which use a continuous coordinate representing the protonation state. ? ? The present method allows for a molecular treatment of the solvent, while still enabling an efficient sampling of protonation states, without spending much time in unphysical states. The method also allows for either of the equivalent carboxylate oxygens to become protonated, using a single coordinate, unlike other methods which treat the possible protonation of the two oxygens by introducing an additional coordinate. ?

The protonation state is strongly dependent on the local geometry. If the neighboring groups are rotated so that they are distal, the pKa of that group is about $1 \mathrm{pH}$ unit less than if one or more neighboring groups are proximal (Table ??). Previous all-atom constant pH simulations found a similar change in the pKa. ${ }^{?}$ Proximity to a sodium ion has a large affect on the protonation state also, changing the pKa by over $1 \mathrm{pH}$ unit (Table ??). A constant $\mathrm{pH}$ simulation of fatty acids, find that the addition of sodium ions decreases the pKa of the carboxylic acid head group by $0.8 \mathrm{pH}$ units relative to simulations without counter ions. ${ }^{?}$ For the de-protonated polymer, representing the high $\mathrm{pH}$ limit, simulations were ran at different sodium ion concentrations, by varying the amount of water. As the sodium concentration increases, the radius of gyration decreases (Table ??). Experimental studies on polymers seem to find mixed results on the effects of sodium on polymer conformation. ? ? Light scattering experiments, on polyacrylic acid (PAA), find that the hydrodynamic radius, $\mathrm{R}_{H}$, does not change at all as a function of $\mathrm{NaCl}$ concentration, up to $1 \mathrm{M}$ ? This study used polymers with molecular weight 82 and 120 KDaltons, or about 1000 to 1400 monomers. Flourescence correlation spectroscopy experiments on PMAA find that $\mathrm{R}_{H}$ decreases as the sodium concentration increases to $1 \mathrm{M} .{ }^{?}$ This was done for polymers of 25, 72 and 105 KDaltons, or 250, 720, and 1050 monomers. Our results, 
even though the polymers are much smaller, are consistent with the PMAA results, showing a similar small decrease in conformational size.

The CG model for the carboxylic acids captures fairly well many properties, despite the approximations made by the model, including the lack of hydrogen interaction sites and the lack of any long-ranged interactions. The models presented here can be combined with similar models for water, ${ }^{?}$ ions, ${ }^{?}$ alkanes, ${ }^{?}$ ethers, ${ }^{?}$ and peptoids, ${ }^{?}$ to allow the simulation a larger range of polymeric materials.

\section{Acknowledgements}

This material is based upon work supported by the U.S. Department of Energy, Office of Science, Basic Energy Sciences, under EPSCoR Grant No. DE-SC0012432 with additional support from the Louisiana Board of Regents. We gratefully acknowledge computer time allotted by the Louisiana Optical Network Initiative (LONI).

\section{References}

() Cistola, D. P.; Hamilton, J. A.; Jackson, D.; Small, D. M. Ionization and phase behavior of fatty acids in water: application of the Gibbs phase rule. Biochemistry 1988, 27, 1881-1888.

() Yatvin, M.; Kreutz, W.; Horwitz, B.; Shinitzky, M. pH-sensitive liposomes: possible clinical implications. Science 1980, 210, 1253-1255.

() Drummand, D. C.; Zignani, M.; Leroux, J.-C. Current status of pH-sensitive liposomes in drug delivery. Prog. Lipid Res. 2000, 39, 409-460.

() Phoeung, T.; Aubron, P.; Rydzek, G.; Lafleur, M. pH-Triggered release from 
nonphospholipid LUVs modulated by the pKa of the included fatty acid. Langmuir 2010, 26, 12769-12776.

() Dai, S.; Ravi, P.; Tam, K. C. pH-responsive polymers: synthesis, properties, and applications. Soft Matter 2008, 4, 435-449.

() Stillinger, F. H.; Weber, T. A. Computer simulation of local order in condensed phases of silicon. Phys. Rev. B 1986, 31, 5262-5271.

() Molinero, V.; Moore, E. B. Water modeled as an intermediate element between carbon and silicon. J. Phys. Chem. B 2009, 113, 4008-4016.

() Larini, L.; Lu, L.; Voth, G. A. The multiscale coarse-graining method. VI. Implementation of three-body coarse-grained potentials. J. Chem. Phys. 2010, 132, 164107.

() Das, A.; Andersen, H. C. The multiscale coarse-graining method. IX. A general method for construction of three body coarse-grained force field. J. Chem. Phys. 2012, 136, 194114.

() Lu, J.; Qiu, Y.; Baron, R.; Molinero, V. Coarse-graining of TIP4P/2005, TIP4P$\mathrm{Ew}, \mathrm{SPC} / \mathrm{E}$, and TIP3P to monatomic anisotropic water models using relative entropy minimization. J. Chem. Theory Comput. 2014, 10, 4104-4120.

() Jacobson, L. C.; Molinero, V. A methane-water model for coarse-grained simulations of solutions and clathrate hydrates. J. Phys. Chem. B 2010, 114, 73027311.

() Song, B.; Molinero, V. Thermodynamic and structural signatures of waterdriven methane-methane attraction in coarse-grained $\mathrm{mW}$ water. J. Chem. Phys. 2013, 139, 054511. 
() Gyawali, G.; Sternfield, S.; Kumar, R.; Rick, S. W. Coarse-grained models of aqueous and pure liquid alkanes. J. Chem. Theory Comput. 2017, 13, 38463853.

() DeMille, R. C.; Molinero, V. Coarse-grained ions without charges: Reproducing the solvation structure of $\mathrm{NaCl}$ in water using short-ranged potentials. J. Chem. Phys. 2009, 131, 034107.

() Raubenolt, B.; Gyawali, G.; Tang, W.; Wong, K. S.; Rick, S. W. Coarse-grained simulations of aqueous thermorepsonsive polyethers. Polymers 2018, 10, 475.

() Marrink, S. J.; Tieleman, D. P. Perspective on the Martini model. Chem. Soc. Rev. 2013, 42, 6801.

() Izvekov, S.; Voth, G. A. A multiscale coarse-graining method for biomolecular systems. J. Phys. Chem. B 2005, 109, 2469-2473.

() Chen, W.; Morrow, B. H.; Shi, C.; Shen, J. K. Recent development and application of constant pH molecular dynamics. Molecular Simulation 2014, 40, $830-838$.

() Mongan, J.; Case, D. A.; McCammon, J. A. Constant pH molecular dynamics in generalized Born implicit solvent. J. Comput. Chem. 2004, 25, 2038-2048.

() Bürgi, R.; Kollman, P. A.; van Gunsteren, W. F. Simulating proteins at constant pH: An approach combining molecular dynamics and Monte Carlo simulation. Proteins: Structure, Function, and Bioinformatics 2002, 47, 469-480.

() Donnini, S.; Tegeler, F.; Groenhof, G.; Grubmüller, H. Constant pH molecular dynamics in explicit solvent with lambda-dynamics. J. Chem. Theory Comput. 2011, \%, 1962-1978. 
() Goh., G. B.; Knight, J. L.; Brooks, III, C. L. Constant pH molecular dynamics simulations of nucleic acids in explicit solvent. J. Chem. Theory Comput. 2012, $8,36-46$.

() Baptista, A. M.; Teixeira, V. H.; Soares, C. M. Constant-pH molecular dynamics using stochastic titration. J. Chem. Phys. 2002, 117, 4184-4200.

() Wallace, J. A.; Shen, J. K. Continuous constant pH molecular dynamics in explicit solvent with pH-based replica exchange. J. Chem. Theory Comput. 2011, 7, 2617-2629.

() Swails, J. M.; York, D. M.; Roitberg, A. E. Constant pH replica exchange molecular dynamics in explicit solvent using discrete protonation states: Implementation, testing, and Validation. J. Chem. Theory Comput. 2014, 10, 1341-1352.

() Enciso, M.; Schütte, C.; Delle Site, L. A pH-dependent coarse-grained model for peptides. Soft Matter 2013, 9, 6118-6127.

() Enciso, M.; Schütte, C.; Delle Site, L. Influence of $\mathrm{pH}$ and sequence in peptide aggregation via molecular simulation. J. Chem. Phys. 2015, 143, 243130.

() Drew Bennett, W. F.; Chen, A. W.; Donnini, S.; Groenhof, G.; Tieleman, D. P. Constant $\mathrm{pH}$ simulations with the coarse-grained MARTINI model Application to oleic acid aggregates. Can. J. Chem. 2013, 91, 839-846.

() Khandogin, J.; Brooks, III, C. L. Toward the accurate first-principles prediction of ionization equilibria in proteins. Biochemistry 2006, 45, 9363-9373.

() Yukawa, H. On the interaction of elementary particles. I. Proceedings of the Physico-Mathematical Society of Japan. 3rd Series 1935, 17, 48-57. 
() Jacobson, L. C.; Kirby, R. M.; Molinero, V. How short is too short for the interactions of a water potential? Exploring the parameter space of a coarsegrained water model using uncertainty quantification. J. Phys. Chem. B 2014, $118,8190-8202$.

() Jorgensen, W. L.; Madura, J. D.; Swenson, C. J. Optimized intermolecular potential functions for liquid hydrocarbons. J. Am. Chem. Soc. 1984, 106, 66386646.

() Jorgensen, W. L.; Maxwell, D. S.; Tirado-Rives, J. Development and testing of the OPLS all-atom force field on conformational energetis and properties of organic liquids. J. Am. Chem. Soc. 1996, 118, 11225-11236.

() Abascal, J. L. F.; Vega, C. A general purpose model for the condensed phases of water: TIP4P/2005. J. Chem. Phys. 2005, 123, 234505.

() Abraham, M. H.; Whiting, G. S.; Fuchs, R.; Chambers, E. J. Thermodynamics of solute transfer from water to hexadecane. J. Chem. Soc.-Perkin Trans. 1990, 2, 291-300.

() Rizzo, R. C.; Aynechi, T.; Case, D. A.; Kuntz, I. D. Estimation of absolute free energies of hydration using continuum methods: Accuracy of partial charge models and optimization of nonpolar contributions. J. Chem. Theory Comput. 2006, 2, 128-139.

() Eliassaf, J.; Silberberg, A. The gelation of aqueous solutions of polymethacrylic acid. Polymer 1962, 3, $555-564$.

() Higashi, N.; Matsumoto, T.; Niwa, M. Chain length discrimination of water- 
soluble polymers by a poly(methacrylic acid) or poly(oxyethylene) segmentcarrying assemblies at the air-water interface. Langmuir 1994, 10, 4651-4656.

() Peljhan, S.; Z̆agar, E.; Cerkovnik, J.; Kogej, K. Strong intermolecular association between short poly(ethacrylic acid) chains in aqueous solutions. J. Phys. Chem. B 2009, 113, 2300-2309.

() Chockalingam, R.; Natarajan, U. Self-association behaviour of atactic polymethacrylic acid in aqueous solution investigated by atomistic molecular dynamics simulations. Molecular Simulation 2015, 41, 1110-1121.

() Daily, M. D.; Baer, M. D.; Mundy, C. J. Divalent ion parameterization strongly affects conformation and interactions of an anionic biomimetic polymer. J. Phys. Chem. B 2016, 120, 2198-2208.

() Annapureddy, H. V. R.; Dang, L. X. Molecular mechanism of specific ion interactions between alkali cations and acetate anion in aqueous solution: A molecular dynamics study. J. Phys. Chem. B 2012, 116, 7492-7498.

() Marinelli, F.; Almagor, L.; Hiller, R.; Giladi, M.; Khananshvili, D.; FaraldoGómez, J. D. Sodium recognition by the $\mathrm{Na}+\mathrm{Ca} 2+$ exchanger in the outwardfacing conformation. Proceedings of the National Academy of Sciences 2014, 111, E5354-E5362.

() Lee, M. S.; Brooks, III, F. R. S. C. L. ConstantpH molecular dynamics using continuous titration coordinates. Proteins: Structure, Function, and Bioinformatics 2004, 56, 738-752.

() Itoh, S. G.; Damjanović, A.; Brooks, B. R. pH replica-exchange method based on 
discrete protonation states. Proteins: Structure, Function, and Bioinformatics 2011, 79, 3420-3436.

() Swails, J. M.; Roitberg, A. E. Enhancing conformation and protonation state sampling of hen egg white lysozyme using $\mathrm{pH}$ replica exchange molecular dynamics. J. Chem. Theory Comput. 2012, 8, 4393-4404.

() Plimpton, S. Fast parallel algorithms for short-range molecular dynamics. J. Comput. Phys. 1995, 117, 1-19.

() van der Spoel, D.; Lindahl, E.; Hess, B.; Groenhof, G.; Mark, A. E.; Berendsen, H. J. C. GROMACS: Fast, flexible and free. J. Comp. Chem. 2005, 26, $1701-1718$.

() Mezei, M. The finite difference thermodynamic integration, tested on calculating the hydration free energy difference between acetone and dimethylamine in water. J. Chem. Phys. 1987, 86, 7084-7088.

() Beutler, T. C.; Mark, A. E.; van Schaik, R. C.; Gerber, P. R.; van Gunsteren, W. F. Avoiding singularities and numerical instabilities in free energy calculations based on molecular simulations. Chem. Phys. Lett. 1994, 222, 529539.

() A git repository for the free energy routines is hosted at https://github.com/ ggyawali/pair_sw_soft/tree/master.

() Sharma, A.; Smith, J. D.; Walters, K. B.; Rick, S. W. Constant pH simulations of pH responsive polymers. J. Chem. Phys. 2016, 145, 234906.

() Ju, S. P.; Lee, W. J.; Huang, C. I.; Cheng, W. Z.; Chung, Y. T. Structure 
and dynamics of water surrounding the poly(methacrylic acid): A molecular dynamics study. J. Chem. Phys. 2007, 126, 224901.

() Sulatha, M. S.; Natarajan, U. Origin of the difference in structural behavior of poly(acrylic acid) and poly(methacrylic acid) in aqueous solution discerned by explicit-solvent explicit-ion MD simulations. Ind. Eng. Chem. Res. 2011, 50, $11785-11796$.

() Zhang, J.; Peppas, N. A. Synthesis and characterization of pH- and temperaturesensitive poly(methacrylic acid)/poly(N-isopropylacrylamide) interpenetrating polymeric networks. Macromolecules 2000, 33, 102-107.

() Pristinski, D.; Kozlovskaya, V.; Sukkishvili, S. A. Fluorescence correlation spectroscopy studies of diffusion of a weak polyelectrolyte in aqueous solutions. $J$. Chem. Phys. 2005, 122, 014907.

() Ikawa, T.; Abe, K.; Honda, K.; Tsuchida, E. Interpolymer complex between poly(ethylene Oxide) and poly(carboxylic Acid). J. Polym. Sci., Polym. Chem. Ed. 1975, 13, 1505-1514.

() Ruiz-Pérez, L.; Pryke, A.; Sommer, M.; Battaglia, G.; Soutar, I.; Swanson, L.; Geoghegan, M. Conformation of poly(methacrylic acid) chains in dilute aqueous solution. Macromolecules 2008, 41, 2203-2211.

() Wang, X.; Ye, X.; Zhang, G. Investigation of pH-induced conformational change and hydration of poly(methacrylic acid) by analytical ultracentrifugation. Soft Matter 2015, 11, 5381-5388.

() Dong, H.; Du, H.; Qian, X. Prediction of pKa Values for oligo-methacrylic acids 
using combined classical and quantum approaches. J. Phys. Chem. Lett. 2009, $113,12857-12859$.

() Khandogin, J.; Brooks, III, C. L. Constant pH molecular dynamics with proton tautomerism. Biophysical J. 2006, 89, 141-157.

() Morrow, B. H.; Koenig, P. H.; Shen, J. K. Atomistic simulations of pHdependent self-assembly of micelle and bilayer from fatty acids. J. Chem. Phys. 2012, 137, 194902.

() Reith, D.; Müller, B.; Müller-Plathe, F.; Wiegand, S. How does the chain extension of poly (acrylic acid) scale in aqueous solution? A combined study with light scattering and computer simulation. J. Chem. Phys. 2002, 116, 9100-9106.

() Du, P.; Rick, S. W.; Kumar, R. Towards a coarse-grained model of the peptoid backbone: the case of N,N-diemethylacetamide. Phys. Chem. Chem. Phys. 2018, 20, 23386-23396. 
Table 1: Bonded parameters.

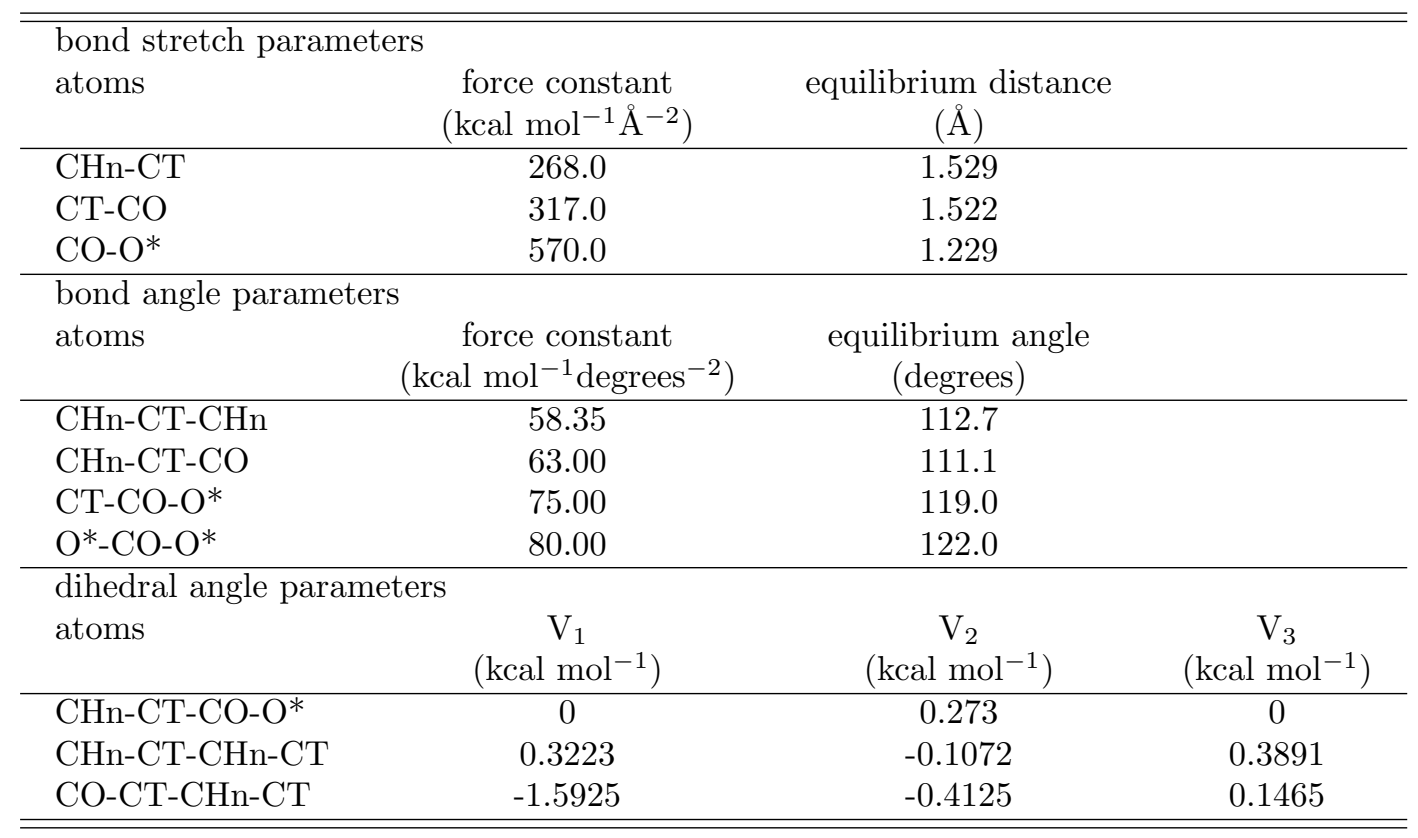


Table 2: Two-body potential parameters for the carboxylic acids, previously published parameters for water, ${ }^{?}$ sodium ${ }^{?}$ and methyl carbons.

\begin{tabular}{|c|c|c|c|}
\hline & & $\sigma(\AA)$ & $\epsilon(\mathrm{kcal} / \mathrm{mol})$ \\
\hline $\mathrm{CH}_{3}$ & $\mathrm{CH}_{3}$ & 4.64 & 0.10 \\
\hline $\mathrm{CH}_{2}$ & $\mathrm{CH}_{2}$ & 5.08 & 0.072 \\
\hline $\mathrm{CO}$ & $\mathrm{CO}$ & 4.50 & 0.141 \\
\hline COA & $\mathrm{COA}$ & 4.20 & 0.010 \\
\hline $\mathrm{COA}$ & CH3 & 4.50 & 0.200 \\
\hline $\mathrm{COA}$ & $\mathrm{CH} 2$ & 4.70 & 0.180 \\
\hline OA & OA & 4.0 & 0 \\
\hline $\mathrm{O}$ & $\mathrm{O}$ & 3.1 & 0.05 \\
\hline $\mathrm{OH}$ & $\mathrm{OH}$ & 2.2 & 0.6 \\
\hline $\mathrm{O}$ & $\mathrm{OH}$ & 2.05 & 1.0 \\
\hline $\mathrm{OA}$ & $\mathrm{OH}$ & 2.20 & 2.18 \\
\hline OA & $\mathrm{O}$ & 3.10 & 0.05 \\
\hline $\mathrm{CH}_{3}$ & OA & 3.60 & 0.400 \\
\hline $\mathrm{CH}_{3}$ & $\mathrm{O}$ & 4.0 & 0.120 \\
\hline $\mathrm{CH}_{3}$ & $\mathrm{OH}$ & 3.90 & 0.130 \\
\hline $\mathrm{CH}_{2}$ & OA & 3.70 & 0.380 \\
\hline $\mathrm{CH}_{2}$ & $\mathrm{O}$ & 3.70 & 0.110 \\
\hline $\mathrm{CH}_{2}$ & $\mathrm{OH}$ & 3.70 & 0.120 \\
\hline COA & OA & 4.20 & 0.010 \\
\hline COA & $\mathrm{O}$ & 3.80 & 0.100 \\
\hline $\mathrm{COA}$ & $\mathrm{OH}$ & 4.00 & 0.220 \\
\hline $\mathrm{CO}$ & OA & 3.675 & 0.280 \\
\hline $\mathrm{CO}$ & $\mathrm{O}$ & 3.655 & 0.260 \\
\hline $\mathrm{CO}$ & $\mathrm{OH}$ & 3.675 & 0.210 \\
\hline $\mathrm{CH}_{3}$ & $\mathrm{H}_{2} \mathrm{O}$ & 4.250 & 0.165 \\
\hline $\mathrm{CH}_{2}$ & $\mathrm{H}_{2} \mathrm{O}$ & 4.290 & 0.1222 \\
\hline COA & $\mathrm{H}_{2} \mathrm{O}$ & 3.70 & 1.3 \\
\hline $\mathrm{CO}$ & $\mathrm{H}_{2} \mathrm{O}$ & 4.10 & 0.025 \\
\hline OA & $\mathrm{H}_{2} \mathrm{O}$ & 2.15 & 7.00 \\
\hline $\mathrm{O}$ & $\mathrm{H}_{2} \mathrm{O}$ & 3.1 & 0.340 \\
\hline $\mathrm{OH}$ & $\mathrm{H}_{2} \mathrm{O}$ & 2.6 & 0.800 \\
\hline $\mathrm{CH}_{3}$ & $\mathrm{Na}^{+}$ & 3.700 & 0.220 \\
\hline $\mathrm{CH}_{2}$ & $\mathrm{Na}^{+}$ & 3.800 & 0.140 \\
\hline COA & $\mathrm{Na}^{+}$ & 2.600 & 0.010 \\
\hline $\mathrm{CO}$ & $\mathrm{Na}^{+}$ & 4.100 & 0.025 \\
\hline OA & $\mathrm{Na}^{+}$ & 1.900 & 3.100 \\
\hline $\mathrm{O}$ & $\mathrm{Na}^{+}$ & 1.900 & 1.100 \\
\hline $\mathrm{OH}$ & $\mathrm{Na}^{+}$ & 1.850 & 0.700 \\
\hline $\mathrm{H}_{2} \mathrm{O}$ & $\mathrm{H}_{2} \mathrm{O}$ & 2.3925 & 6.189 \\
\hline $\mathrm{Na}^{+}$ & $\mathrm{H}_{2} \mathrm{O}$ & 1.850 & 16.0 \\
\hline
\end{tabular}

Table 3: Yukawa potential parameters for the acetate ion and previously published parameters for sodium.

\begin{tabular}{llll}
\hline \hline & & $\kappa\left(\AA^{-} 1\right)$ & A (kcal/mol) \\
\hline $\mathrm{O}$ (acetate) & $\mathrm{O}$ (acetate) & 1.8 & 276.75 \\
$\mathrm{Na}^{+}$ & $\mathrm{Na}^{+}$ & 1.8 & 1107 \\
\hline \hline
\end{tabular}


Table 4: Three-body potential parameters for the acetate ion and previously published parameters for water and sodium. ? ${ }^{?}$ The central atom is given first.

\begin{tabular}{|c|c|c|c|c|c|}
\hline & & & $\overline{\epsilon \epsilon(\mathrm{kcal} / \mathrm{mol})}$ & $\bar{\lambda}$ & $\overline{c \cos \left(\theta_{0}\right)}$ \\
\hline $\mathrm{OH}$ & $\mathrm{OH}$ & $\mathrm{OH}$ & 0.6 & 10 & $-1 / 3$ \\
\hline $\mathrm{O}$ & $\mathrm{OH}$ & $\mathrm{OH}$ & 1.0 & 10 & $-1 / 3$ \\
\hline $\mathrm{OH}$ & $\mathrm{O}$ & $\mathrm{OH}$ & 1.0 & 10 & $-1 / 3$ \\
\hline $\mathrm{O}$ & $\mathrm{O}$ & $\mathrm{OH}$ & 1.0 & 10 & $-1 / 3$ \\
\hline $\mathrm{OH}$ & $\mathrm{O}$ & $\mathrm{O}$ & 1.0 & 10 & $-1 / 3$ \\
\hline $\mathrm{OH}$ & $\mathrm{OH}$ & $\mathrm{OA}$ & 2.18 & 8 & $-1 / 3$ \\
\hline $\mathrm{OH}$ & $\mathrm{OA}$ & $\mathrm{OA}$ & 2.18 & 8 & $-1 / 3$ \\
\hline $\mathrm{OH}$ & $\mathrm{O}$ & $\mathrm{OA}$ & 1.38 & 8 & $-1 / 3$ \\
\hline $\mathrm{O}$ & $\mathrm{OH}$ & $\mathrm{OA}$ & 1.0 & 8 & $-1 / 3$ \\
\hline $\mathrm{OA}$ & $\mathrm{OH}$ & $\mathrm{OH}$ & 2.18 & 8 & $-1 / 3$ \\
\hline $\mathrm{OA}$ & $\mathrm{OA}$ & $\mathrm{OH}$ & 2.18 & 8 & $-1 / 3$ \\
\hline $\mathrm{OA}$ & $\mathrm{O}$ & $\mathrm{OH}$ & 1.0 & 8 & $-1 / 3$ \\
\hline $\mathrm{OH}$ & $\mathrm{CO}$ & $\mathrm{OH}$ & 1.0 & 10 & $-1 / 3$ \\
\hline $\mathrm{OH}$ & $\mathrm{CO}$ & $\mathrm{O}$ & 1.0 & 10 & $-1 / 3$ \\
\hline $\mathrm{OH}$ & $\mathrm{CO}$ & $\mathrm{OA}$ & 2.18 & 8 & $-1 / 3$ \\
\hline $\mathrm{OH}$ & $\mathrm{CO}$ & $\mathrm{H}_{2} \mathrm{O}$ & 0.8 & 8 & $-1 / 3$ \\
\hline $\mathrm{OA}$ & $\mathrm{OA}$ & $\mathrm{H}_{2} \mathrm{O}$ & 7.0 & 2.85 & $-1 / 3$ \\
\hline $\mathrm{H}_{2} \mathrm{O}$ & $\mathrm{OA}$ & $\mathrm{OA}$ & 7.0 & 8 & $-1 / 3$ \\
\hline $\mathrm{OA}$ & $\mathrm{H}_{2} \mathrm{O}$ & $\mathrm{H}_{2} \mathrm{O}$ & 7.0 & 8 & $-1 / 3$ \\
\hline $\mathrm{H}_{2} \mathrm{O}$ & $\mathrm{OA}$ & $\mathrm{H}_{2} \mathrm{O}$ & 7.0 & 8 & $-1 / 3$ \\
\hline $\mathrm{O}$ & $\mathrm{O}$ & $\mathrm{H}_{2} \mathrm{O}$ & 0.340 & 8 & $-1 / 3$ \\
\hline $\mathrm{O}$ & $\mathrm{OH}$ & $\mathrm{H}_{2} \mathrm{O}$ & 0.340 & 8 & $-1 / 3$ \\
\hline $\mathrm{H}_{2} \mathrm{O}$ & $\mathrm{O}$ & $\mathrm{O}$ & 0.340 & 8 & $-1 / 3$ \\
\hline $\mathrm{O}$ & $\mathrm{H}_{2} \mathrm{O}$ & $\mathrm{H}_{2} \mathrm{O}$ & 0.340 & 8 & $-1 / 3$ \\
\hline $\mathrm{H}_{2} \mathrm{O}$ & $\mathrm{O}$ & $\mathrm{H}_{2} \mathrm{O}$ & 0.340 & 8 & $-1 / 3$ \\
\hline $\mathrm{OH}$ & $\mathrm{OH}$ & $\mathrm{H}_{2} \mathrm{O}$ & 0.80 & 8 & $-1 / 3$ \\
\hline $\mathrm{OH}$ & $\mathrm{O}$ & $\mathrm{H}_{2} \mathrm{O}$ & 0.80 & 4 & $-1 / 3$ \\
\hline $\mathrm{H}_{2} \mathrm{O}$ & $\mathrm{OH}$ & $\mathrm{OH}$ & 0.800 & 8 & $-1 / 3$ \\
\hline $\mathrm{OH}$ & $\mathrm{H}_{2} \mathrm{O}$ & $\mathrm{H}_{2} \mathrm{O}$ & 0.800 & 8 & $-1 / 3$ \\
\hline $\mathrm{H}_{2} \mathrm{O}$ & $\mathrm{OH}$ & $\mathrm{H}_{2} \mathrm{O}$ & 0.800 & 8 & $-1 / 3$ \\
\hline $\mathrm{H}_{2} \mathrm{O}$ & $\mathrm{OH}$ & $\mathrm{O}$ & 0.4 & 8 & $-1 / 3$ \\
\hline $\mathrm{OA}$ & $\mathrm{H}_{2} \mathrm{O}$ & $\mathrm{OH}$ & 3.0 & 8 & $-1 / 3$ \\
\hline $\mathrm{OA}$ & $\mathrm{H}_{2} \mathrm{O}$ & $\mathrm{O}$ & 1.54 & 5 & $-1 / 3$ \\
\hline $\mathrm{OH}$ & $\mathrm{OA}$ & $\mathrm{H}_{2} \mathrm{O}$ & 1.02 & 8 & $-1 / 3$ \\
\hline $\mathrm{H}_{2} \mathrm{O}$ & $\mathrm{OA}$ & $\mathrm{O}$ & 1.54 & 8 & $-1 / 3$ \\
\hline $\mathrm{H}_{2} \mathrm{O}$ & $\mathrm{OA}$ & $\mathrm{OH}$ & 2.37 & 8 & $-1 / 3$ \\
\hline $\mathrm{O}$ & $\mathrm{OA}$ & $\mathrm{H}_{2} \mathrm{O}$ & 1.54 & 5 & $-1 / 3$ \\
\hline $\mathrm{OA}$ & $\mathrm{H}_{2} \mathrm{O}$ & $\mathrm{Na}^{+}$ & 3.1 & 2 & $-1 / 3$ \\
\hline $\mathrm{H}_{2} \mathrm{O}$ & $\mathrm{OA}$ & $\mathrm{Na}^{+}$ & 3.1 & 2 & $-1 / 3$ \\
\hline $\mathrm{Na}^{+}$ & $\mathrm{OA}$ & $\mathrm{H}_{2} \mathrm{O}$ & 3.1 & 2 & $-1 / 3$ \\
\hline $\mathrm{H}_{2} \mathrm{O}$ & $\mathrm{O}$ & $\mathrm{Na}^{+}$ & 1.1 & 2 & $-1 / 3$ \\
\hline $\mathrm{O}$ & $\mathrm{H}_{2} \mathrm{O}$ & $\mathrm{Na}^{+}$ & 1.1 & 2 & $-1 / 3$ \\
\hline $\mathrm{Na}^{+}$ & $\mathrm{O}$ & $\mathrm{H}_{2} \mathrm{O}$ & 1.1 & 2 & $-1 / 3$ \\
\hline $\mathrm{H}_{2} \mathrm{O}$ & $\mathrm{H}_{2} \mathrm{O}$ & $\mathrm{H}_{2} \mathrm{O}$ & 6.189 & 23.15 & $-1 / 3$ \\
\hline $\mathrm{Na}^{+}$ & $\mathrm{H}_{2} \mathrm{O}$ & $\mathrm{H}_{2} \mathrm{O}$ & 16.0 & 7 & $-1 / 3$ \\
\hline $\mathrm{H}_{2} \mathrm{O}$ & $\mathrm{Na}^{+}$ & $\mathrm{H}_{2} \mathrm{O}$ & 16.0 & 7 & $-1 / 3$ \\
\hline $\mathrm{H}_{2} \mathrm{O}$ & $\mathrm{Na}^{+}$ & $\mathrm{Na}^{+}$ & 16.0 & 7 & $-1 / 3$ \\
\hline $\mathrm{Na}^{+}$ & $\mathrm{H}_{2} \mathrm{O}$ & $\mathrm{Na}^{+}$ & 16.0 & 7 & $-1 / 3$ \\
\hline
\end{tabular}


Table 5: Properties of a 20 unit long PMAA for the protonated and de-protonated form at various sodium concentrations.

\begin{tabular}{llllllll}
\hline \hline & {$\left[\mathrm{Na}^{+}\right]$} & \multicolumn{2}{c}{ radius of gyration $(\AA)$} & \multicolumn{2}{c}{ fraction proximal } & \multicolumn{2}{c}{ number of contact $\mathrm{Na}^{+}$} \\
& & syndiotactic & isotactic & syndiotactic & isotactic & syndiotactic & isotactic \\
\hline protonated & $0 \mathrm{~m}$ & $5.78 \pm 0.04$ & $5.67 \pm 0.04$ & $0.28 \pm 0.01$ & $0.77 \pm 0.02$ & N/A & N/A \\
protonated & $0.25 \mathrm{~m}$ & $5.80 \pm 0.03$ & $5.73 \pm 0.05$ & $0.30 \pm 0.01$ & $0.80 \pm 0.02$ & $0.03 \pm 0.02$ & $0.03 \pm 0.02$ \\
de-protonated & $0 \mathrm{~m}$ & $10.8 \pm 0.6$ & $9.7 \pm 0.4$ & $0.20 \pm 0.02$ & $0.30 \pm 0.02$ & $\mathrm{~N} / \mathrm{A}$ & $\mathrm{N} / \mathrm{A}$ \\
de-protonated & $0.25 \mathrm{~m}$ & $10.7 \pm 0.5$ & $9.7 \pm 0.3$ & $0.19 \pm 0.03$ & $0.35 \pm 0.02$ & $3.0 \pm 0.5$ & $3.2 \pm 0.3$ \\
de-protonated & $0.50 \mathrm{~m}$ & $10.2 \pm 0.4$ & $8.8 \pm 0.4$ & $0.22 \pm 0.02$ & $0.39 \pm 0.02$ & $5.6 \pm 0.5$ & $4.9 \pm 0.5$ \\
\hline \hline
\end{tabular}

Table 6: Radius of gyration for $\mathrm{n}=20$ PMAA from different simulation studies.

\begin{tabular}{llll}
\hline \hline tacticity & {$\left[\mathrm{Na}^{+}\right]$} & \multicolumn{2}{c}{ radius of gyration $(\AA)$} \\
& & protonated & de-protonated \\
\hline syndiotactic, this work & $0.25 \mathrm{~m}$ & $5.80 \pm 0.03$ & $10.7 \pm 0.5$ \\
isotactic, this work & $0.25 \mathrm{~m}$ & $5.73 \pm 0.05$ & $9.7 \pm 0.3$ \\
syndiotactic? & 0 & $7.3 \pm 0.1$ & $12.0 \pm 0.1$ \\
isotactic? & 0 & $7.0 \pm 0.5$ & $12.4 \pm 0.1$ \\
atactic $^{?}$ & $0.2 \mathrm{~m}$ & $6.4,6.7$ & $9.9,10.0$ \\
\hline \hline
\end{tabular}

Table 7: Values of the pKa and the Hill cooperativity parameters.

\begin{tabular}{lllllllllll}
\hline \hline chain length & \multicolumn{2}{c}{ total } & \multicolumn{2}{c}{$\mathrm{Na}^{+}$far } & \multicolumn{2}{c}{$\mathrm{Na}^{+}$close } & \multicolumn{2}{c}{ distal } & \multicolumn{3}{c}{ proximal } \\
& $\mathrm{pKa}$ & $\mathrm{n}$ & $\mathrm{pKa}$ & $\mathrm{n}$ & $\mathrm{pKa}$ & $\mathrm{n}$ & $\mathrm{pKa}$ & $\mathrm{n}$ & $\mathrm{pKa}$ & $\mathrm{n}$ \\
\hline 1 & $5.04 \pm 0.06$ & 1 & $5.09 \pm 0.06$ & 1 & $4.3 \pm 0.2$ & 1 & & & & \\
2 & $5.8 \pm 0.1$ & $0.91 \pm 0.09$ & $5.9 \pm 0.1$ & $0.93 \pm 0.05$ & $5.2 \pm 0.2$ & $1.3 \pm 0.2$ & $5.7 \pm 0.1$ & $1.02 \pm 0.05$ & $6.7 \pm 0.2$ & $0.5 \pm 0.1$ \\
20 isotactic & $8.4 \pm 0.3$ & $0.55 \pm 0.08$ & $8.5 \pm 0.3$ & $0.5 \pm 0.1$ & $6.2 \pm 0.6$ & $0.7 \pm 0.2$ & $7.8 \pm 0.5$ & $0.8 \pm 0.2$ & $8.2 \pm 0.5$ & $0.4 \pm 0.1$ \\
20 syndiotactic & $8.4 \pm 0.3$ & $0.65 \pm 0.07$ & $8.5 \pm 0.3$ & $0.6 \pm 0.1$ & $6.4 \pm 0.6$ & $0.6 \pm 0.2$ & $8.1 \pm 0.2$ & $0.8 \pm 0.1$ & $8.9 \pm 0.4$ & $0.4 \pm 0.1$ \\
\hline \hline
\end{tabular}




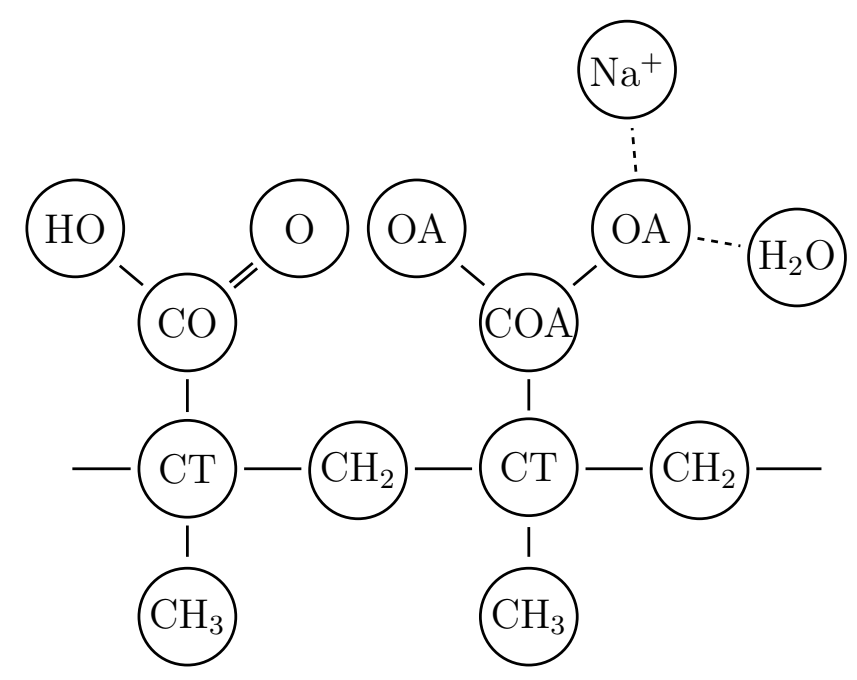

Figure 1: Two units of the poly(methacrylic acid) structure, showing the protonated and de-protonated forms and the coarse-grained groups (circles). 

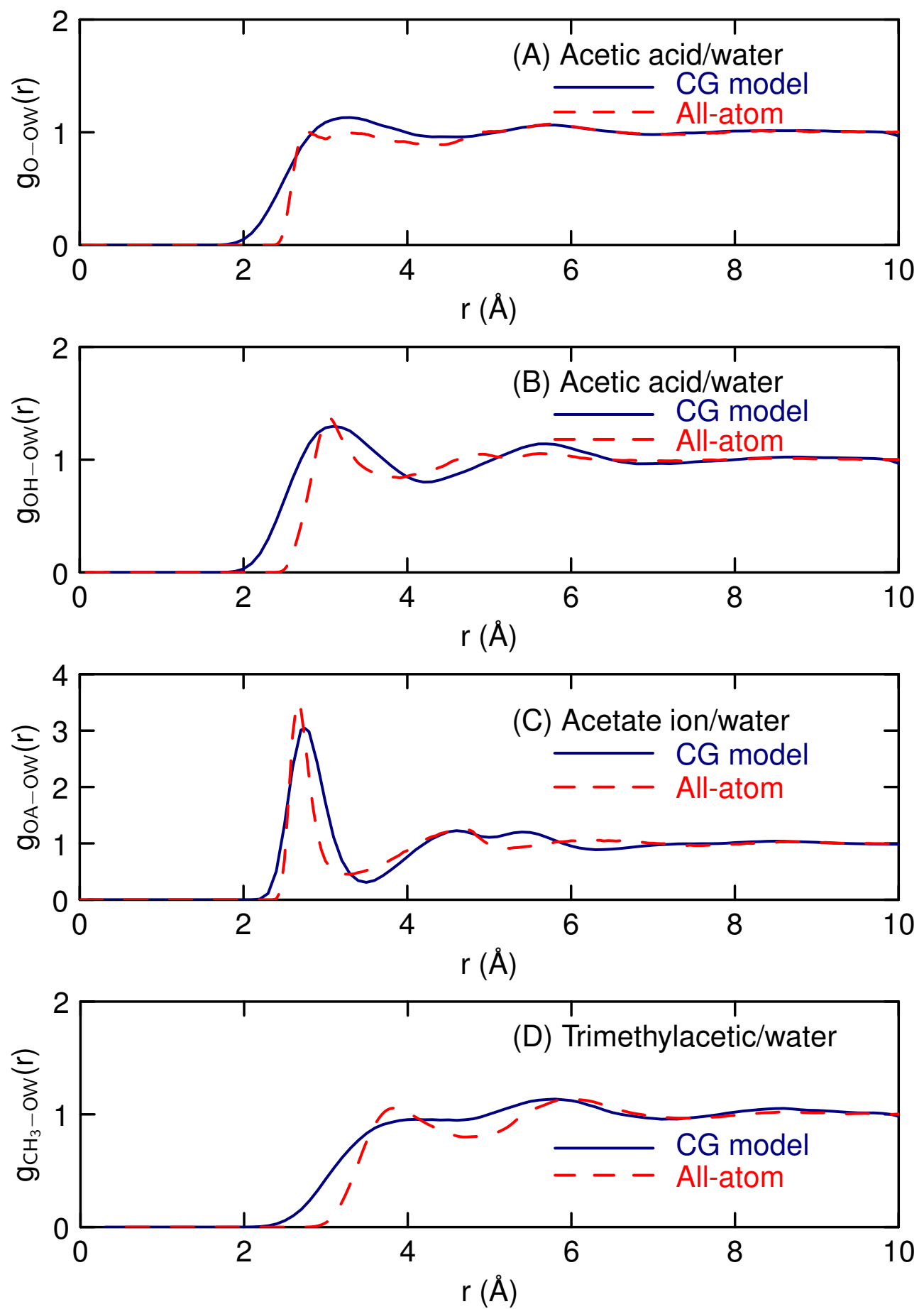

Figure 2: Coarse-grained and all-atom pair correlation functions between water oxygen and oxygen atoms on the acetic acid (A and B) and the acetate ion $(\mathrm{C})$, and between water oxygen and the methyl carbon on trimethylacetic acid (D). 


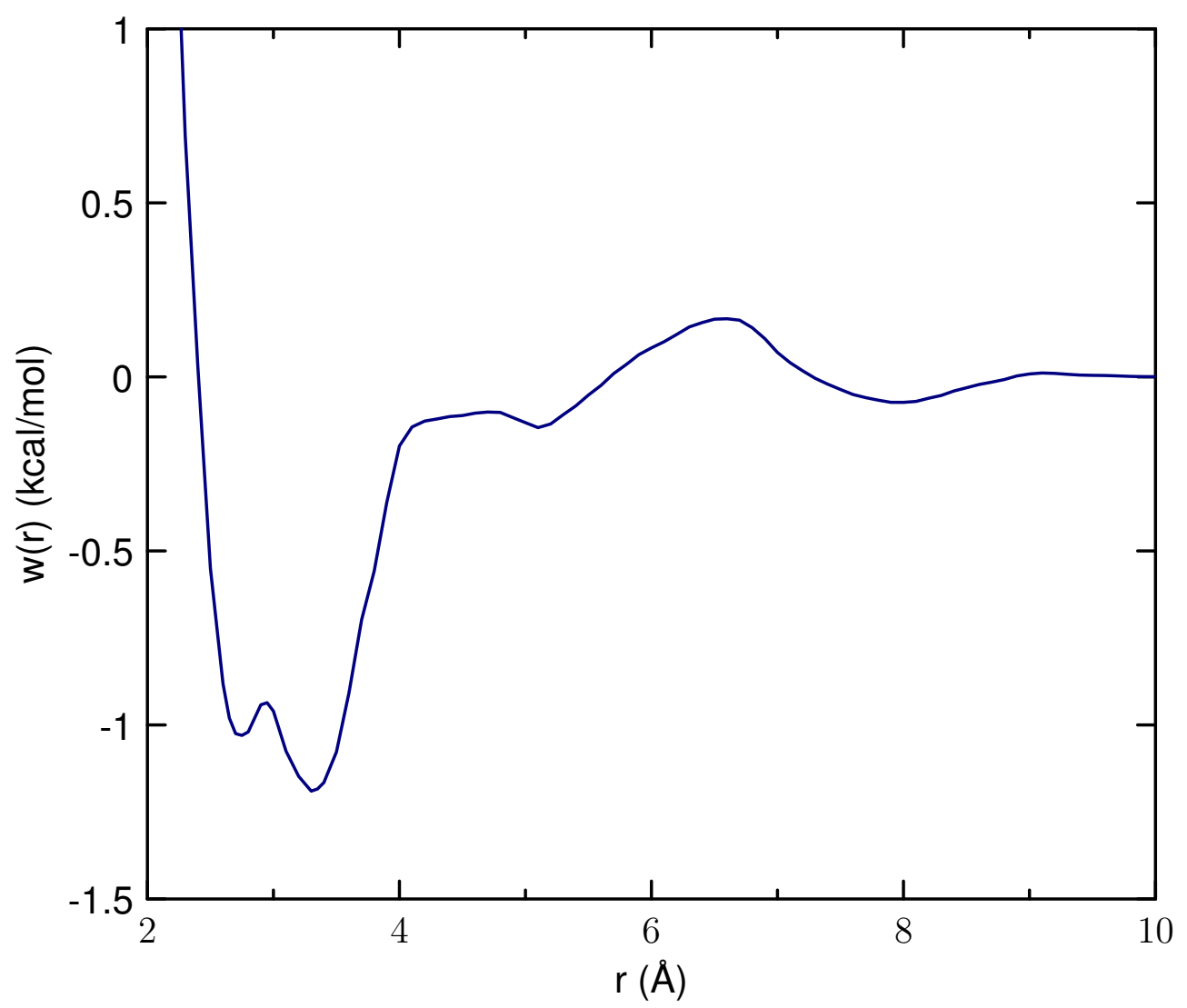

Figure 3: Potential of mean force between the acetate and sodium ions, relative to the distance between the carboxylate carbon and the sodium ion. 


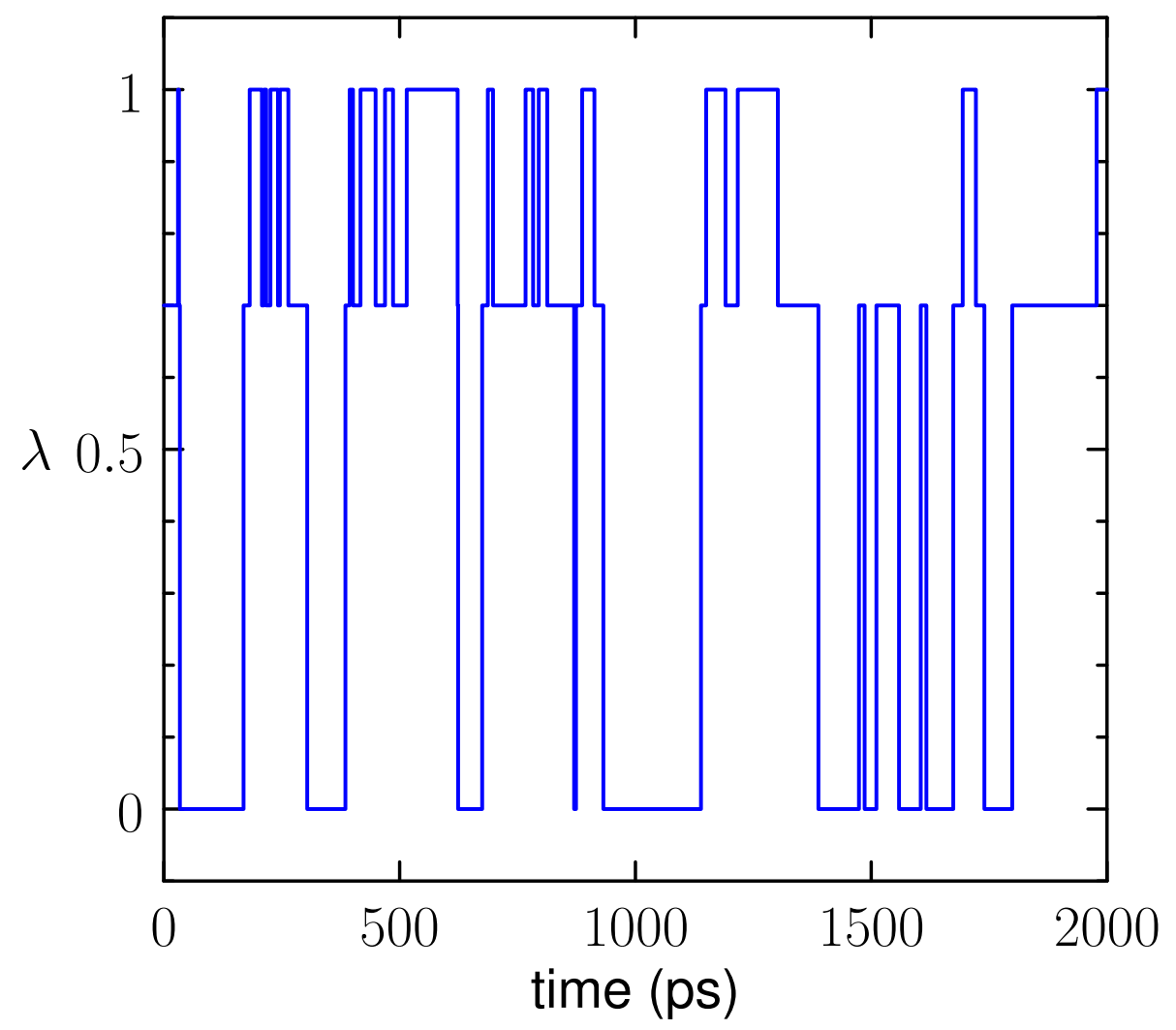

Figure 4: The protonation state variable, $\lambda$, as a function of time for aqueous trimethylacetic acid. 


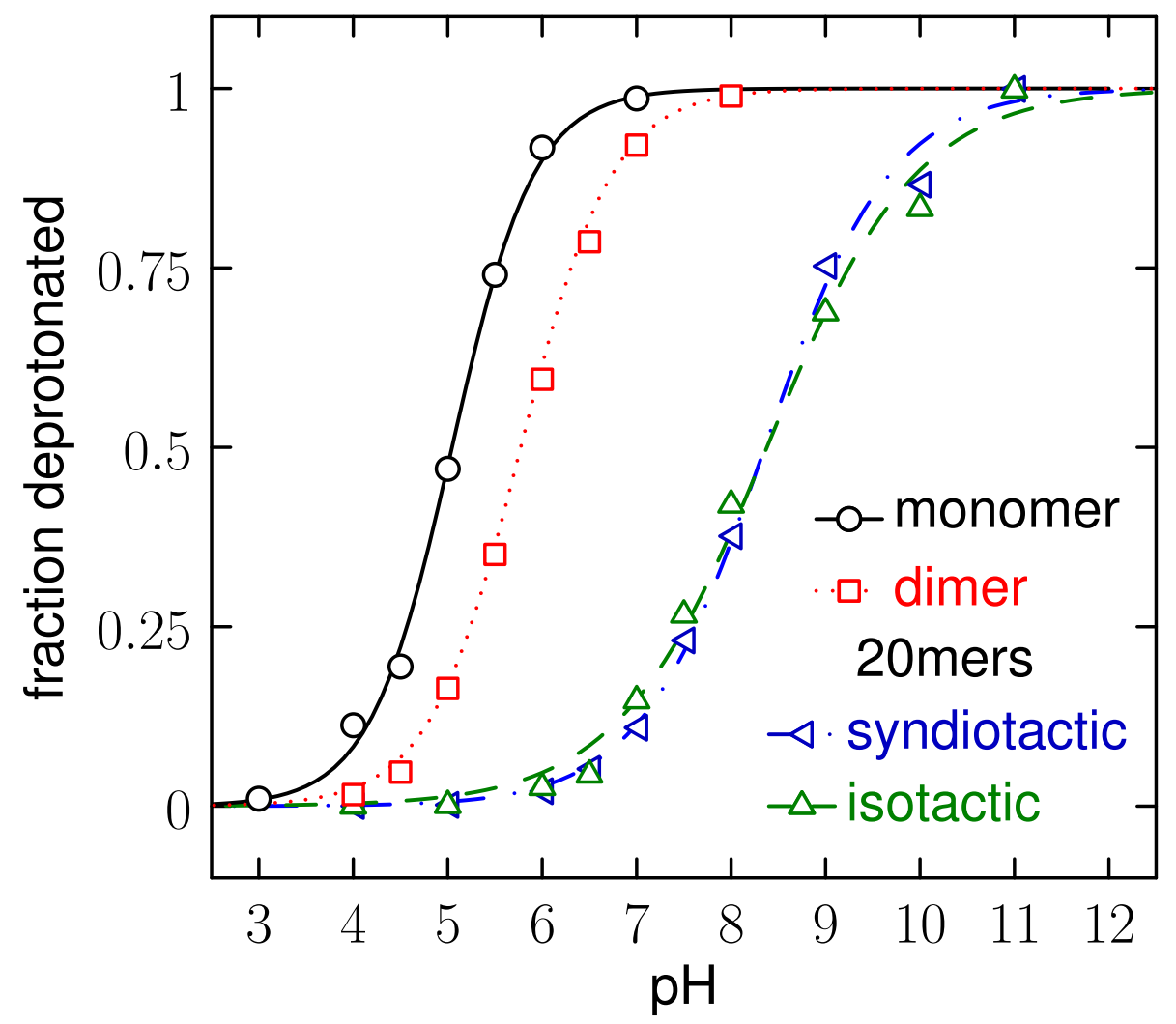

Figure 5: Titration curves for oligomers of various lengths. 


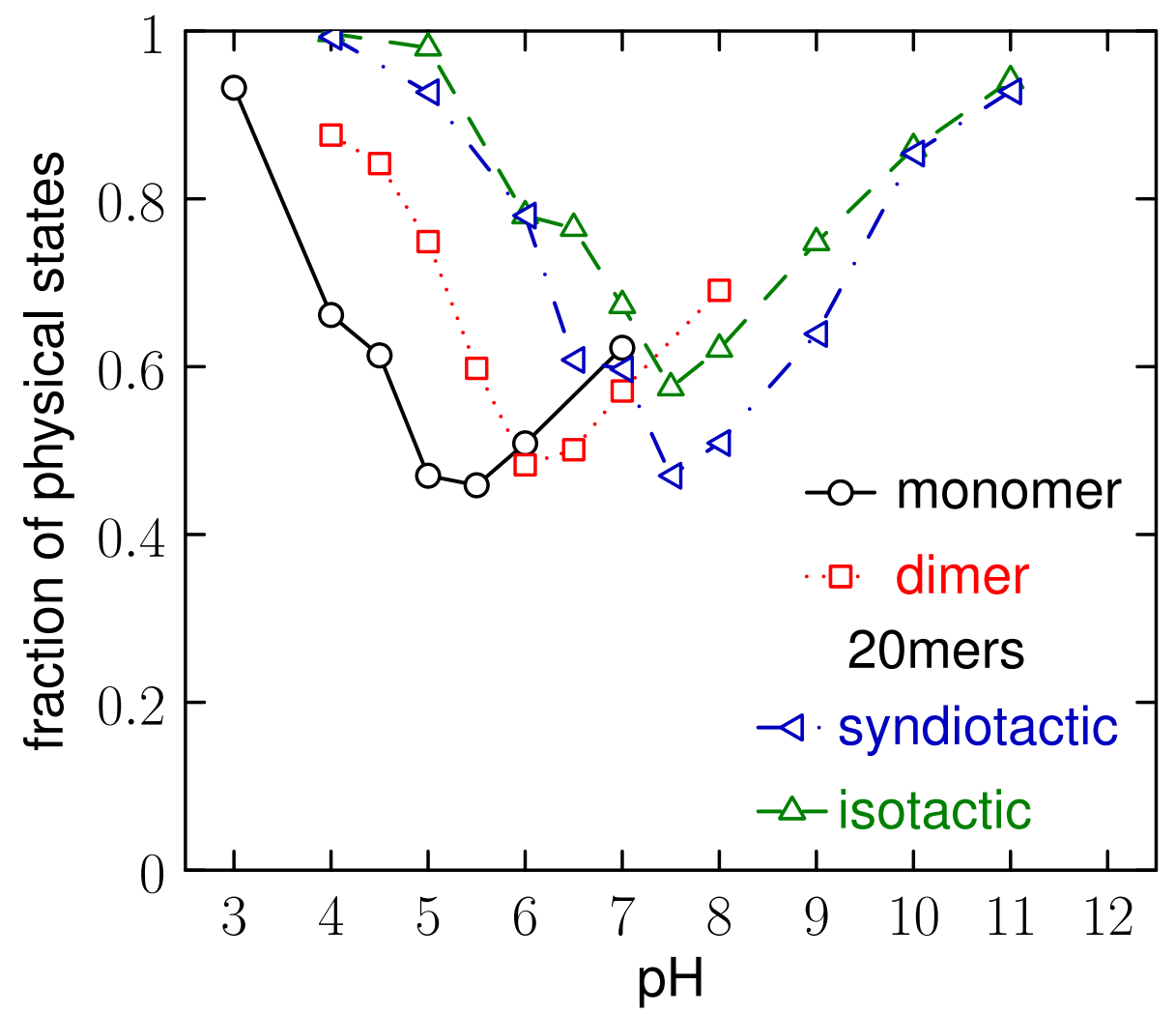

Figure 6: The fraction of physical states as a function of $\mathrm{pH}$. 

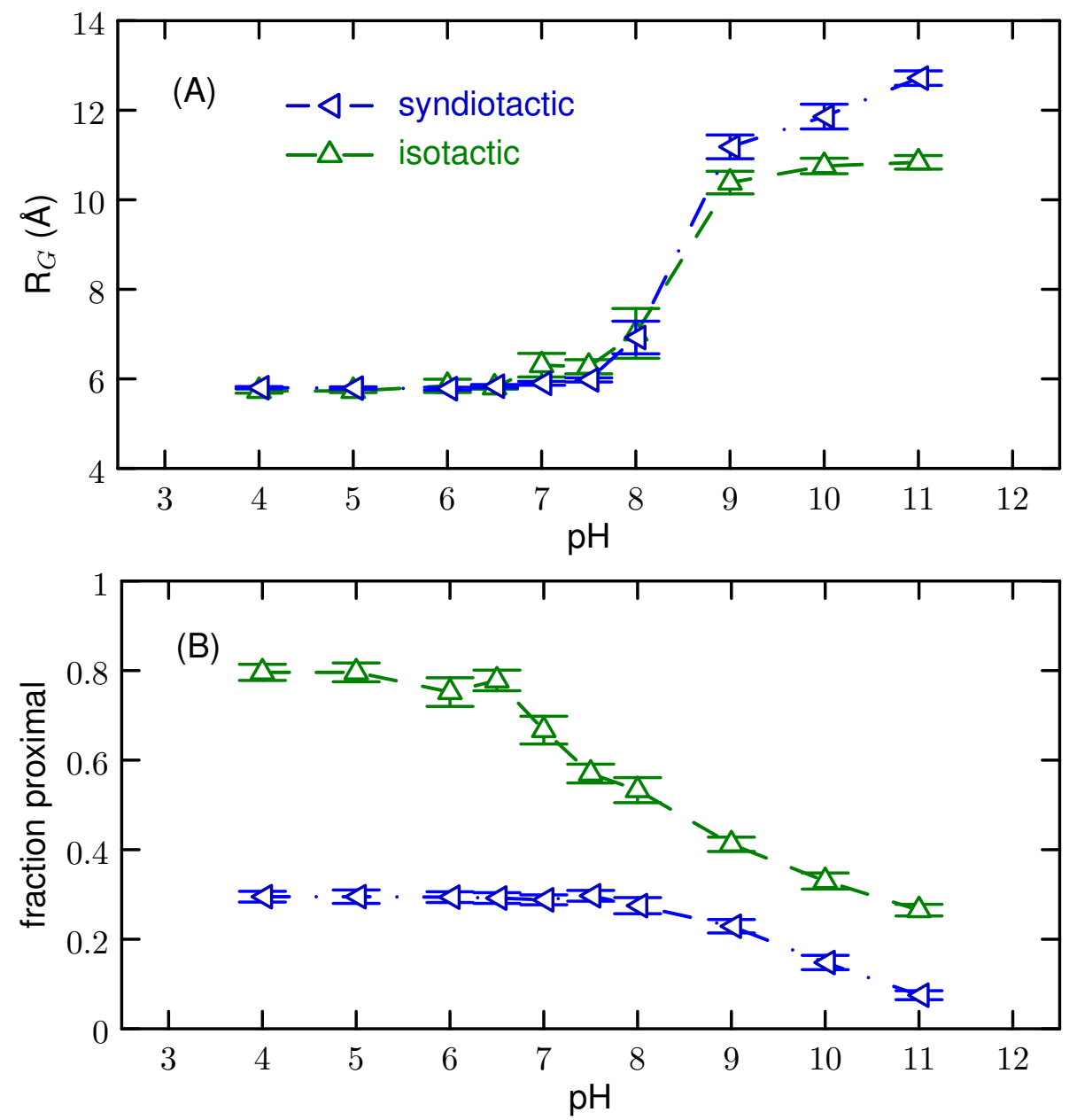

Figure 7: Radius of gyration (A) and fraction proximal nearest neighbors (B) as a function of $\mathrm{pH}$ for the isotactic and syndiotactic $20 \mathrm{mer}$. 